\title{
PENGARUH KESIAPAN BELAJAR DAN INTERAKSI TEMAN SEBAYA TERHADAP HASIL BELAJAR MATEMATIKA SISWA KELAS VII SMP NEGERI 5 SAMARINDA
}

\author{
Sugeng ${ }^{1)}$ \\ Yulia Dewi Arief Fanti ${ }^{2)}$ \\ Azainil $^{3)}$ \\ 1), 2), 3) Program Studi Pendidikan Matematika, Universitas Mulawarman \\ Email: ${ }^{1)}$ sugeng@fkip.unmul.ac.id
}

\begin{abstract}
ABSTRAK
Penelitian ex post facto ini bertujuan untuk mengetahui pengaruh kesiapan belajar dan interaksi teman sebaya terhadap hasil belajar matematika siswa kelas VII SMP Negeri 5 Samarinda tahun ajaran 2017/2018. Populasi dalam penelitian ini adalah sejumlah 189 siswa kelas VII SMP Negeri 5 Samarinda. Sampel dalam penelitian ini sebanyak 150 siswa atau 5 kelas yang dipilih menggunakan metode/teknik cluster random sampling. Berdasarkan hasil analisis inferensial dengan menggunakan regresi linier ganda diperoleh persamaan model regresi dugaan yang menunjukkan bahwa terdapat pengaruh kesiapan belajar dan interaksi teman sebaya terhadap hasil belajar matematika siswa (Sig. $=0,000$ pada $\alpha=0,05$ ); kontribusi kedua variabel bebas itu sebesar $R^{2}=0,403$. Hasil pengujian variabel kesiapan belajar diperoleh $\mathrm{Sig}=0,000$; sehingga diperoleh terdapat pengaruh kesiapan belajar terhadap hasil belajar matematika. Untuk variabel interaksi teman sebaya diperoleh $\operatorname{Sig}=0,012$; sehingga diperoleh terdapat pengaruh interaksi teman sebaya terhadap hasil belajar matematika.
\end{abstract}

Kata Kunci: Kesiapan belajar, Interaksi teman sebaya, Hasil belajar matematika

\begin{abstract}
The type of this research is ex post facto research, which aims to determine the effect of readiness of learning and peer interactions on the results of learning mathematics students class VII SMP Negeri 5 Samarinda academic year 2017/2018. The population of this study was all VII grade students of SMP Negeri 5 Samarinda totaling 189 students. The sample in this study were 150 students or 5 classes selected using the cluster random sampling method/technique. Based on the results of inferential analysis using multiple linear regression obtained equation of the alleged regression model that shows that there is an influence of learning readiness and peer interaction on student mathematics learning outcomes (Sig. $=0,000$ at $\alpha=0.05$ ); the contribution of the two independent variables was $R^{2}=0.403$. The results of testing the readiness of learning variables obtained Sig.=0,000; so it is obtained that there is an influence of learning readiness on mathematics learning outcomes. For peer interaction variables obtained Sig. $=0.012$; so that there is an influence of peer interaction on mathematics learning outcomes.
\end{abstract}


Keywords: Readiness of learning, Peer interactions, Mathematics learning outcomes PENDAHULUAN

Pendidikan merupakan salah satu cara dalam usaha peningkatan kualitas sumber daya manusia melalui aktivitas belajar. Kegiatan belajar siswa dapat dipengaruhi oleh dua faktor utama, yaitu faktor intern dan faktor ekstern. Faktor intern adalah faktor yang ada di dalam diri individu yang sedang belajar, sedangkan faktor ekstern adalah faktor yang ada di luar individu. sekolah, dan (Slameto, 2010:54).
Berdasarkan hasil observasi dengan guru mata pelajaran matematika kelas VII SMP Negeri 5 Samarinda, hasil belajar matematika siswa masih tergolong rendah karena masih banyak siswa yang mendapatkan nilai kurang dari Kriteria Ketuntasan Minimum (KKM) yaitu 70. Hal ini dapat dilihat dari rata-rata nilai ulangan matematika siswa kelas VII SMP Negeri 5 Samarinda tahun ajaran 2016/ 2017 yang terdapat pada Tabel 1.

Tabel 1. Rata-Rata Nilai Ulangan Matematika Siswa Kelas VII di SMP Negeri 5 Samarinda Tahun Ajaran 2016/2017

\begin{tabular}{|c|c|c|c|}
\hline No. & Kelas & Rata-rata nilai & \multirow{3}{*}{ KKM } \\
\hline 1 & VII-A & 65 & \multirow{3}{*}{70} \\
\hline 2 & VII-B & 58 & \\
\hline 3 & VII-C & 60 \\
\hline 4 & VII-D & 65 & \\
\hline 5 & VII-E & 57 & \\
\hline 6 & VII-F & 62 & \\
\hline
\end{tabular}

(Sumber: Dokumen Guru SMP Negeri 5 Samarinda)

Berdasarkan hasil wawancara dengan guru mata pelajaran matematika kelas VII di SMP Negeri 5 Samarinda, diperoleh kondisi siswa sebelum memulai belajar siswa terkesan tidak siap untuk belajar yaitu masih ada yang makan di kantin dan juga berkeliaran di luar kelas pada saat jam belajar mau dimulai. Selanjutnya guru memberikan informasi bahwa masih banyak siswa yang lupa mengerjakan PR (pekerjaan rumah) ataupun sudah mengerjakan PR tetapi lupa membawanya, lupa membawa buku paket atau catatan, lupa membawa alat tulis seperti pulpen penggaris dan lain-lain. Halhal tersebut dijadikan siswa sebagai alasan untuk tidak mencatat materi yang diajarkan oleh guru di kelas. Dari masalah-masalah tersebut penulis melihat siswa-siswa di sekolah tersebut memiliki masalah dalam hal kesiapan belajar.

Selain masalah kesiapan belajar, Adapun masalah lain yaitu mengenai interaksi siswa. Interaksi teman sebaya banyak menimbulkan pengaruh pembelajaran karena pada umumnya siswa SMP yang baru menginjak usia remaja masih labil sehingga sering terpengaruh oleh perilaku temantemannya dalam satu kelompok.

Guru melihat adanya siswa yang berinteraksi positif dengan temannya, misalkan sering belajar kelompok dan saling membantu dalam pelajaran. Disisi lain, Guru juga memaparkan ada siswa yang sering membolos, merokok, suka 
bermain game online dan juga suka berkumpul sepulang sekolah. Dari interaksi-interaksi siswa dengan temantemannya peneliti melihat siswa mengalami masalah dalam hal interaksi teman sebaya. Hal ini diperkuat oleh Maidatud Dhorifah (2017) yang menunjukkan bahwa ada pengaruh yang positif dan signifikan antara interaksi sosial terhadap hasil belajar siswa kelas V sedangkan pada jenjang SMP, terdapat korelasi yang kuat antara kesiapan belajar dengan hasil belajar matematika SMP kelas VIII SMP Negeri 1 Singingi (Dila Nuryati, dkk 2019).

Slameto (2003:113) mengemukakan bahwa kesiapan belajar adalah keseluruhan kondisi seseorang yang membuatnya siap untuk memberi respon/ jawaban dengan cara tertentu terhadap suatu situasi. Indikator-indikator kesiapan belajar yang digunakan dalam penelitian ini adalah kondisi fisik, kondisi mental, kondisi emosional, kebutuhan, kesiapan materi dan pengetahuan.

Mohammad Ali dan Mohammad Asrori (2011:87) mendefinisikan interaksi sebagai hubungan timbal balik dua orang atau lebih, dan masing-masing orang yang terlibat di dalamnya memainkan peran secara aktif. Adapun indikator-indikator interaksi teman sebaya yang digunakan dalam penelitian ini adalah keterbukaan antar individu dalam kelompok, kerjasama antar individu dalam kelompok, frekuensi hubungan antar individu dalam kelompok.

Agus Syarifuddin (2019) mengungkapkan bahwa prestasi belajar matematika adalah hasil yang dicapai siswa setelah mengikuti pelajaran matematika baik berupa perubahan perilaku maupun kecakapan yang dinyatakan dengan simbol, angkat, maupun huruf.

\section{METODE PENELITIAN}

Penelitian ini menggunakan rancangan ex post facto, yang terdiri atas tiga variabel, yaitu 2 variabel bebas, dan 1 variabel terikat. Variabel bebas pada penelitian ini adalah kesiapan belajar $\left(X_{1}\right)$, dan interaksi teman sebaya $\left(X_{2}\right)$, dan variabel terikat pada penelitian ini adalah hasil belajar matematika $(Y)$.

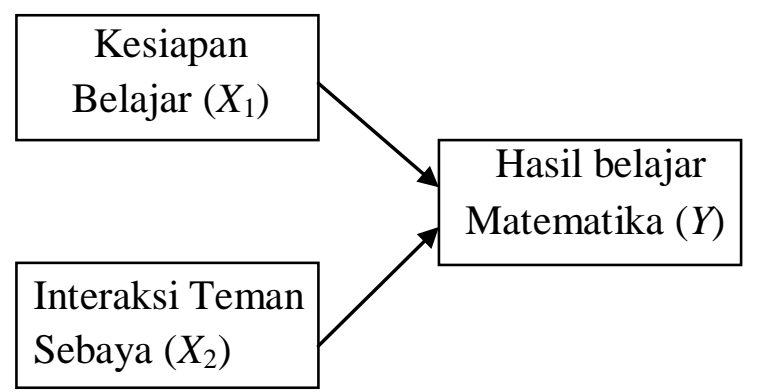

Gambar 1. Desain Penelitian

Teknik pengambilan sampel yang digunakan pada penelitian ini adalah cluster random sampling. Adapun sampelnya adalah

Tabel 2. Sampel Penelitian

\begin{tabular}{|c|c|c|}
\hline No. & Kelas & Jumlah siswa \\
\hline 1. & VII-A & 29 Siswa \\
\hline 2. & VII-B & 32 Siswa \\
\hline 3. & VII-C & 30 Siswa \\
\hline 4. & VII-E & 29 Siswa \\
\hline 5. & VII-F & 30 Siswa \\
\hline \multicolumn{2}{|c|}{ Jumlah } & 150 Siswa \\
\hline
\end{tabular}

(Sumber: Dokumen Guru Matematika SMPN 9 Samarinda 2016/2017)

Teknik pengumpulan data yang digunakan yaitu angket dan tes hasil belajar matematika. Angket berisi pernyataan terkait dengan kesiapan belajar dan interaksi teman sebaya sedangkan tes hasil belajar matematika adalah materi pokok bilangan bulat pada 
semester I dalam bentuk uraian dengan di uji cobakan terlebih dahulu dengan menggunakan uji validitas dan reliabilitas pada kelas VII D sebanyak 32 orang.

Statistik deskriptif digunakan untuk mengungkapkan distribusi skor dari masing-masing variabel, baik variabel bebas maupun variabel terikat. Statistik inferensial menggunakan regresi linier ganda. Sebelum pengujian hipotesis, terlebih dahulu dilakukan uji persyaratan analisis atau uji asumsi yang terdiri dari uji normalitas, uji homogenitas, dan uji linieritas. Setelah pengujian asumsi terpenuhi, kemudian menguji hipotesis penelitian menggunakan regresi linier ganda dengan taraf signifikan pengujian $5 \%$ atau sebesar 0,05 .

HASIL PENELITIAN DAN PEMBAHASAN

\section{Hasil Penelitian}

\section{a. Deskriptif Data}

\section{1) Kesiapan Belajar $\left(X_{1}\right)$}

Data variabel kesiapan belajar siswa dalam penelitian ini diukur dengan menggunakan angket berjumlah 31 butir Dari deskripsi data diperoleh rata-rata skor 87,33 dan standar deviasi sebesar 9,951; serta untuk skor tertinggi dan terendah masing-masing sebesar 106 dan 61. Deskripsi data variabel secara lengkap dapat dilihat pada Tabel 3.

Berdasarkan Tabel 3, terlihat bahwa skor kebiasaan belajar siswa kelas VII di SMP Negeri 5 Samarinda lebih banyak berada pada kategori sedang, yaitu sebanyak 61 siswa dengan persentase 40,7\%. Berdasarkan distribusi tersebut, dapat dikatakan bahwa kesiapan belajar siswa kelas VII di SMP Negeri 5 Samarinda tergolong sedang.

2) Interaksi Teman Sebaya $\left(X_{2}\right)$

Data variabel interaksi teman sebaya siswa dalam penelitian ini diukur dengan menggunakan angket berjumlah 26 butir pernyataan yang telah divalidasi secara empiris sebelumnya. Dari deskripsi data diperoleh rata-rata skor 74,11 dan standar deviasi sebesar 9,316. Selain itu, untuk skor tertinggi dan terendah masingmasing sebesar 100 dan 50. Deskripsi data variabel secara lengkap dapat dilihat pada Tabel 4.

Berdasarkan data pada Tabel 4, terlihat bahwa skor interaksi teman sebaya siswa kelas VII di SMP Negeri 5 Samarinda lebih banyak berada pada kategori sedang, yaitu sebanyak 55 siswa dengan persentase $36,7 \%$. Berdasarkan distribusi tersebut, dapat dikatakan bahwa interaksi teman sebaya siswa kelas VII di SMP Negeri 5 Samarinda tergolong sedang.

\section{3) Hasil Belajar Matematika Siswa $(Y)$}

Data variabel hasil belajar matematika siswa dalam penelitian ini diukur dengan menggunakan tes soal uraian berjumlah 7 butir soal yang telah divalidasi secara empiris sebelumnya.

Dari deskripsi data diperoleh ratarata skor 53,87 dan standar deviasi sebesar 15,119. Selain itu, skor tertinggi dan terendah masing-masing sebesar 80 dan 14. Deskripsi data variabel secara lengkap dapat dilihat pada Table 5: Berdasarkan Tabel 5, terlihat bahwa skor hasil belajar matematika siswa kelas VII di SMP Negeri 5 Samarinda lebih banyak berada pada kategori sedang, yaitu 
sebanyak 52 siswa dengan persentase $34,7 \%$. Berdasarkan distribusi tersebut, dapat dikatakan bahwa hasil belajar matematika siswa kelas VII di SMP Negeri 5 Samarinda tergolong sedang.

\section{b. Analisis Inferensial}

Analisis inferensial yang digunakan pada penelitian ini adalah regresi linear ganda.

\section{1) Uji Normalitas}

Berdasarkan hasil analisis menggunakan program SPSS 21, diperoleh bahwa taraf signifikan statistik lebih dari taraf signifikan pengujian $(\alpha)$ yaitu 0,207>0,05 maka $\mathrm{H}_{0}$ diterima, sehingga dapat disimpulkan bahwa data tes hasil belajar matematika siswa berasal dari populasi yang berdistribusi normal.

Tabel 3. Deskripsi Data dan Distribusi Frekuensi Skor Kesiapan Belajar

\begin{tabular}{|c|c|c|c|}
\hline \multicolumn{2}{|c|}{ Skor Kebiasaan Belajar } & \multirow{2}{*}{ Frekuensi } & \multirow{2}{*}{$\begin{array}{c}\text { Persentase } \\
(\%)\end{array}$} \\
\hline Interval & Kategori & & \\
\hline $102<X$ & Sangat Tinggi & 4 & 2,7 \\
\hline $92<X \leq 102$ & Tinggi & 47 & 31,3 \\
\hline $82<X \leq 92$ & Sedang & 61 & 40,7 \\
\hline $72<X \leq 82$ & Rendah & 22 & 14,7 \\
\hline$X \leq 72$ & Sangat Rendah & 16 & 10,7 \\
\hline \multicolumn{2}{|c|}{ Jumlah } & 150 & 100,0 \\
\hline \multicolumn{2}{|c|}{ Skor Maksimum } & \multicolumn{2}{|c|}{106} \\
\hline \multicolumn{2}{|c|}{ Skor Minimum } & \multicolumn{2}{|c|}{61} \\
\hline \multicolumn{2}{|c|}{ Rata-rata } & \multicolumn{2}{|c|}{87,33} \\
\hline \multicolumn{2}{|c|}{ Standar Deviasi } & \multicolumn{2}{|c|}{9,951} \\
\hline
\end{tabular}

Tabel 4. Deskripsi Data dan Distribusi Frekuensi Skor Interaksi Teman Sebaya

\begin{tabular}{|c|c|c|c|}
\hline \multicolumn{2}{|c|}{ Skor Interaksi Teman Sebaya } & \multirow{2}{*}{ Frekuensi } & \multirow{2}{*}{$\begin{array}{c}\text { Persentase } \\
(\%)\end{array}$} \\
\hline Interval & Kategori & & \\
\hline $88<X$ & Sangat Tinggi & 4 & 2,7 \\
\hline $79<X \leq 88$ & Tinggi & 51 & 34,0 \\
\hline $67<X \leq 79$ & Sedang & 55 & 36,7 \\
\hline $60<X \leq 67$ & Rendah & 27 & 18,0 \\
\hline$X \leq 60$ & Sangat Rendah & 13 & 8,7 \\
\hline \multicolumn{2}{|c|}{ Jumlah } & 150 & 100,0 \\
\hline \multicolumn{2}{|c|}{ Skor Maksimum } & \multicolumn{2}{|c|}{100} \\
\hline \multicolumn{2}{|c|}{ Skor Minimum } & \multicolumn{2}{|c|}{50} \\
\hline \multicolumn{2}{|c|}{ Rata-rata } & \multicolumn{2}{|c|}{74,11} \\
\hline \multicolumn{2}{|c|}{ Standar Deviasi } & \multicolumn{2}{|c|}{9,316} \\
\hline
\end{tabular}


Tabel 5. Deskripsi Data dan Distribusi Frekuensi Skor Hasil Belajar Matematika

\begin{tabular}{|c|c|c|c|}
\hline \multicolumn{2}{|c|}{ Skor Hasil Belajar } & Frekuensi & $\begin{array}{c}\text { Persentase } \\
(\%)\end{array}$ \\
\hline $77<X$ & Kategori & & 2,7 \\
\hline $61<X \leq 77$ & Sangat Tinggi & 4 & 30,7 \\
\hline $46<X \leq 61$ & Tinggi & 46 & 34,7 \\
\hline $31<X \leq 46$ & Sedang & 52 & 23,3 \\
\hline$X \leq 31$ & Rendah & 35 & 8,7 \\
\hline \multicolumn{2}{|c|}{ Sumgat Rendah } & 13 & 100,0 \\
\hline \multicolumn{2}{|c|}{ Skor Maksimum } & 150 & 80 \\
\hline \multicolumn{2}{|c|}{ Skor Minimum } & \multicolumn{2}{|c|}{14} \\
\hline \multicolumn{2}{|c|}{ Rata-rata } & 33,87 \\
\hline \multicolumn{2}{|c|}{ Standar Deviasi } & \multicolumn{2}{c}{} \\
\hline
\end{tabular}

\section{2) Pemeriksaan Homogenitas}

Berdasarkan hasil analisis menggunakan program SPSS 21.0, terlihat bahwa diagram pencar tidak membentuk suatu pola tertentu. Oleh karena itu, dapat dikatakan bahwa data hasil belajar matematika berasal dari populasi dengan varians homogen.

Pada teknik perhitungan $B-P-G$ test, diperoleh nilai $\chi_{\text {hitung }}^{2}=\frac{11,156}{2}=5,578$ dan $\chi_{\text {tabel }}^{2}=5,991$. Karena nilai $\chi_{\text {hitung }}^{2}<\chi_{\text {tabel }}^{2}$, yaitu 5,578 $<5,991$ maka $\mathrm{H}_{0}$ diterima, sehingga dapat disimpulkan bahwa varians populasi homogen.

\section{3) Uji Linieritas}

Berdasarkan perhitungan menggunakan program SPSS 21, diperoleh taraf signifikan statistik untuk kesiapan belajar terhadap hasil belajar matematika sebesar 0,210 dan taraf signifikan statistik untuk interaksi teman sebaya terhadap hasil belajar matematika sebesar 0,069. Karena kedua taraf signifikan statistik tersebut lebih dari taraf signifikan pengujian yaitu
0,05 maka $\mathrm{H}_{0}$ diterima, sehingga dapat disimpulkan bahwa model regresi linier.

\section{4) Uji Hipotesis Penelitian}

\section{a) Persamaan Model Regresi dan Uji Keberartian Model Regresi}

Berdasarkan hasil perhitungan menggunakan program SPSS 21.0 seperti pada Tabel 6 diperoleh nilai $b_{0}=-32,358, b_{1}=0,642$ dan $b_{2}=0,407$. Nilai $b_{0}$ adalah kontanta pada persamaan model regresi dugaan, untuk $b_{1}$ dan $b_{2}$ masing masing adalah koefisien untuk variabel $X_{1}$ dan $X_{2}$ sehingga diperoleh persamaan regresi dugaannya, yaitu:

$$
\hat{Y}=-32,358+0,642 X_{1}+0,407 X_{2}
$$

Berdasarkan hasil analisis, diperoleh taraf signifikan statistik sebesar $0,000<0,05$ maka $\mathrm{H}_{0}$ ditolak, sehingga dapat disimpulkan bahwa model regresi yang diperoleh berarti. 
Tabel 6. Hasil Analisis Regresi Linier Ganda

\begin{tabular}{|c|c|c|c|}
\hline Variabel & Koefisien & $\boldsymbol{t}_{\text {hitung }}$ & Sig. \\
\hline Konstanta & $-32,358$ & $-3,711$ & 0,000 \\
\hline$X_{1}$ & 0,642 & 4,299 & 0,000 \\
\hline$X_{2}$ & 0,407 & 2,548 & 0,012 \\
\hline$R$ & \multicolumn{3}{|c|}{0,635} \\
\hline$R^{2}$ & 0,403 \\
\hline Probabilitas & 0,000 \\
\hline$F_{\text {hitung }}$ & \multicolumn{3}{|c}{49,580} \\
\hline
\end{tabular}

\section{b) Koefisiesn Determinasi $\left(\boldsymbol{R}^{2}\right)$}

Berdasarkan hasil analisis dengan menggunakan SPSS21.0, diperoleh nilai koefisien determinasi $\left(R^{2}\right)$ sebesar 0,403 yang berarti bahwa kontribusi kesiapan belajar dan interaksi teman sebaya terhadap hasil belajar matematika sebesar $40,3 \%$. Sisanya $57 \%$ dipengaruhi oleh factor lain yang tidak diungkapkan pada penelitian ini.

\section{c) Uji Keberartian Koefisien Regresi}

Berdasarkan hasil analisis dengan menggunakan SPSS 21, diperoleh taraf signifikan statistik sebesar $0,000<0,05$ maka $\mathrm{H}_{0}$ ditolak, sehingga disimpulkan bahwa terdapat pengaruh kesiapan belajar terhadap hasil belajar matematika dengan memperhitungkan variabel lain dalam model. Untuk koefisien interaksi teman sebaya sebesar $0,012<0,05$ maka $H_{0}$ ditolak, sehingga dapat disimpulkan bahwa terdapat pengaruh interaksi teman sebaya terhadap hasil belajar matematika dengan memperhitungkan variabel lain dalam model.

\section{Pembahasan}

Kesiapan belajar merupakan faktor yang dapat mempengaruhi hasil belajar siswa. Hamalik (2009:29) faktor kesiapan turut menentukan hasil belajar. Kesiapan di sini mengandung arti kesiapan mental, sosial, emosional, dan fisik. Kesiapan akan memudahkan siswa untuk belajar untuk mencapai keberhasilan. Dalam penelitian ini, hasil yang diperoleh didukung oleh pendapat Hamalik, bahwa kesiapan belajar memiliki pengaruh positif terhadap hasil belajar yang diperoleh siswa. Hal ini diperkuat oleh Afrizal Putra Bujuri (2015) yang menyatakan terdapat pengaruh motivasi belajar dan kesiapan belajar terhadap hasil belajar matematika siswa SMA Swadhipa.

Hasil penelitian ini juga mendukung hasil penelitian yang juga telah dilakukan pada jenjang SMP, baik penelitian yang menggunakan sampel kelas VIII (SMP Negeri 1 Singingi oleh Dila Nuryati, Abdurrahman, \& Rezi Ariawan. 2019; siswa SMP Negeri 1 Wringinanom oleh Assisca Devisafitri, 2019); maupun siswa Kelas IX (SMP Negeri 1 Banjarnegara oleh Indah Puspicahyani, 2006). Namun juga untuk sampel siswa SMA Negeri 1 Rambatan Kabupaten Tanah Datar (Dessy Mulyani, 2013).

Dalam penelitian ini, ditemukan beberapa pernyataan angket kesiapan belajar dengan rata-rata skor terendah, yang menunjukkan bahwa kesiapan belajar siswa masih kurang baik, seperti masih banyak 
siswa yang tidak mempelajari materi pelajaran matematika yang akan disampaikan guru di pertemuan berikutnya sehingga siswa mengalami kesulitan dalam mengerjakan soal matematika. Dalam hal ini, orang tua dan guru hendaknya lebih sering mengingatkan siswa untuk selalu menyiapkan diri untuk proses belajar mengajar di sekolah. Orangtua dapat selalu memastikan siswa untuk sarapan sebelum berangkat agar kesiapan fisiknya pun baik. Guru pun dapat meminta siswa untuk mengulang materi yang telah diajarkan guru ataupun dapat membaca terlebih dahulu materi yang belum disampaikan agar siswa lebih siap ketika akan mengikuti pelajaran di sekolah khususnya pada mata pelajaran matematika.

Selain itu, dari hasil penelitian, diperoleh bahwa terdapat pengaruh positif interaksi teman sebaya terhadap hasil belajar matematika. Artinya, semakin tinggi interaksi teman sebaya siswa, maka hasil belajar matematika siswa juga akan semakin meningkat. Dengan koefisien regresi interaksi teman sebaya sebesar 0,407 yang berarti setiap kenaikan interaksi teman sebaya sebesar 1 satuan maka akan meningkatkan hasil belajar matematika sebesar 0,407 satuan.

Kisworowati (1992:30) mengemukakan bahwa interaksi teman sebaya adalah hubungan timbal balik antara individu dengan teman-teman yang mempunyai umur tidak jauh berbeda dengan maksud saling memberi rasa aman dalam proses penyesuaian dirinya. Karena interaksi itulah siswa dapat menjalin suatu kegiatan yang dapat menunjang keberhasilan dalam proses pembelajaran. Seorang siswa yang memiliki interaksi dengan teman sebayanya dalam hal positif, seperti melakukan belajar bersama di waktu luang, akan memberikan dampak yang baik pada hasil belajarnya. Sebaliknya, jika siswa saling berinteraksi dengan teman sebayanya dengan hal-hal yang negatif, maka siswa tersebut akan mendapatkan hasil belajar yang kurang baik. Dalam hal ini, hasil yang diperoleh sejalan dengan yang diungkapkan oleh Aunurrahman, bahwa interaksi teman sebaya dapat memberikan pengaruh positif terhadap hasil belajar yang diperoleh siswa. Hasil penelitian yang diperoleh juga relevan dengan penelitian yang dilakukan oleh Miftahul Jannah (2017) tentang pengaruh kebiasaan belajar dan interaksi teman sebaya terhadap hasil belajar matematika kelas XI IPA SMA Negeri 1 Tana Paser tahun ajaran 2015/2016. Berdasarkan hasil penelitian disimpulkan bahwa terdapat pengaruh kebiasaan belajar dan interaksi teman sebaya terhadap hasil belajar matematika kelas XI IPA SMA Negeri 1 Tana Paser tahun ajaran 2015/2016.

Hasil penelitian ini juga mendukung hasil penelitian yang telah dilakukan pada jenjang SD/MI, yakni telah dilakukan penelitian terkait pengaruh interaksi sosial terhadap hasil belajar siswa, hasilnya menunjukkan bahwa ada pengaruh yang positif dan signifikan antara interaksi sosial terhadap hasil belajar siswa kelas V MI (Maidatud Dhorifah (2017). Selain itu, pada jenjang SD/MI, telah dilakukan penelitian pengaruh pergaulan Teman Sebaya dan prestasi belajar siswa Kelas V Sekolah Dasar Gugus Gajah Mada oleh Imam Al Qadr Sidiq (2016)

Dalam penelitian ini, ditemukan beberapa pernyataan angket interaksi teman sebaya dengan rata-rata skor terendah, yang

78 Pengaruh Kesiapan Belajar dan Interaksi Teman Sebaya Sugeng - Yulia Dewi Arief Fanti - Azainil 
menunjukkan interaksi teman sebaya pada siswa masih kurang, seperti siswa jarang membuat jadwal rutin untuk belajar bersama teman-temannya sehingga siswa jarang berkumpul bersama teman-temannya untuk belajar matematika. Oleh karena itu, interaksi teman sebaya penting untuk ditingkatkan agar hasil belajar matematika yang diperoleh dapat meningkat pula. Dalam hal ini, orang tua dan guru hendaknya menasihati siswa atau memberikan masukan bahwa interaksi teman sebaya sangat penting di usia mereka. Dengan memberitahu apa saja halhal baik yang dapat dilakukan bersama teman-teman, guru dapat memberi saran agar siswa membentuk kelompok belajar dengan teman-temannya khususnya mata pelajaran matematika agar hasil belajar matematika siswa dapat maksimal.

\section{KESIMPULAN}

Kesimpulan dari penelitian ini adalah terdapat pengaruh kesiapan belajar dan interaksi teman sebaya terhadap hasil belajar matematika siswa kelas VII SMP Negeri 5 Samarinda tahun ajaran 2017/ 2018. Adapun beberapa saran dari hasil penelitian ini:

1. Bagi guru, berkaitan dengan kesiapan belajar agar senantiasa mengingatkan siswa untuk mempersiapkan diri dalam belajar dengan cara belajar sendiri terlebih dahulu sebelum diajarkan oleh guru. Berkaitan dengan interaksi teman sebaya diharapkan dapat untuk dapat membantu siswa dalam membentuk interaksi teman sebaya yang positif.

2. Bagi sekolah, agar mempertimbangkan langkah/tindakan untuk meningkatkan kesiapan belajar dan interaksi teman sebaya siswa guna meningkatkan hasil belajar matematika siswa.

3. Bagi siswa, berkaitan dengan kesiapan belajar diharapkan siswa agar lebih menyiapkan diri sebelum memulaii pelajaran, meliputi kondisi fisik, emosional, mental, kelengkapan peralatan belajar, terlebih pemahaman akan materi yang telah diajarkan sebelumnya ataupun materi yang akan dipelajari selanjutnya. Berkaitan dengan interaksi teman sebaya agar dapat membentuk interaksi teman sebaya yang positif agar dapat meningkatkan hasil belajar matematika.

\section{DAFTAR PUSTAKA}

Aunurrahman. (2014). Belajar dan Pembelajaran. Alfabeta.

Bujuri, A.P., Pargito, Sudarmi. (2015). Pengaruh Motivasi Belajar dan Kesiapan Belajar Terhadap Hasil Belajar Matematika Siswa SMA Swadhipa. Jurnal Penelitian Geografi. 3(1): 1-14.

Devisafitri, A., \& Pramonoadi. (2019). Hubungan Kesiapan Belajar Siswa dengan Hasil Belajar Siswa Kelas VIII di SMP Negeri 1 Wringinanom Buana Matematika : Jurnal Ilmiah Matematika dan Pendidikan Matematika, 9(2): 73-76.

https://doi.org/10.36456/buanamatem atika.v9i2:.2119

Dhorifah, M. (2017). Pengaruh interaksi sosial terhadap hasil belajar siswa kelas V di Madrasah Ibtidaiyah Mambaul Ulum Sumber Gempol Pagelaran Malang. Universitas Islam Negeri Maulana Malik Ibrahim. 
Mohammad, A. \& Asrori, M. (2011). Psikologi Remaja. Bumi Aksara.

Nuryati, D., Abdurrahman, Ariawan, R. (2019). Pengaruh Kesiapan Belajar Terhadap Hasil Belajar Siswa Kelas VIII di SMP Negeri 1 Singingi. Aksiomatik, 7(2): 1 - 7 .

Slameto. (2010). Belajar dan Faktor-faktor yang Mempengaruhinya. Rineka Cipta.

Subarinah, S. (2006). Inovasi Pembelajaran Matematika SD. Depdiknas.

Syarifuddin, A.. (2019). Pengaruh Pergaulan Teman Sebaya Terhadap Prestasi Belajar Matematika Mahasiswa STKIP Paris Barantai. Program Studi Pendidikan Matematika, STKIP Paris Barantai. CENDEKIA: Jurnal Ilmiah Pendidikan, 7(2): 284-292. https://doi.org/10.33659/cip.v7i2.144 